\title{
ARTICLE
}

Interventions and public health nutrition

\section{Effectiveness of a type 2 diabetes prevention program combining FINDRISC scoring and telephone-based coaching in the French population of bakery/pastry employees}

\author{
Philip Böhme $\mathbb{B}^{1,2} \cdot$ Amandine Luc $^{3} \cdot$ Pascal Gillet $^{4} \cdot$ Nathalie Thilly ${ }^{2,3}$
}

Received: 30 August 2018 / Revised: 26 June 2019 / Accepted: 3 July 2019 / Published online: 17 July 2019

(c) The Author(s) 2019. This article is published with open access

\begin{abstract}
Background/objectives Preventive actions targeting the risk of type 2 diabetes mellitus (T2D) and deployed from the workplace are scarce. This study aimed to measure this T2D risk in a large sample of the bakery/pastry employees in France and to assess the effectiveness of a telephone coaching program in participants with the highest risk.

Subjects/methods A screening survey using the FINDRISC score was conducted by phone among the employees. Those with a moderate risk (score $\geq 12$ and $<15$; body mass index $\geq 25 \mathrm{~kg} / \mathrm{m}^{2}$ ) or high/very high risk (score $\geq 15$ ) were invited to participate in a 6-month coaching program including 6 monthly interviews together with a final evaluation interview three months later. The effects and impact were evaluated using 8 questions on dietary knowledge/behavior as well as the GPAQ (physical activity) and SF-12 (quality of life) questionnaires.

Results There were 19,951 employees eligible for screening (age: $38.0 \pm 13.5$ years, men 49.6\%, mean FINDRISC score $5.9 \pm 4.4$ ). A high/very high score was found in $4 \%$ of individuals. Overall, 1,348 (among 2,018) eligible employees agreed to participate in the coaching program, 630 of whom participated in all interviews. Of the latter, dietary knowledge/behavior $(+1.60)$ and quality of life $(+1.83)$ improved $(P<0.0001)$, with a favorable trend for physical activity $(+0.06, P=0.0756)$. Dietary knowledge/behavior continued to improve in the 581 completers $(+0.17, P=0.0001)$.

Conclusions This two-step prevention program associating T2D risk estimation and a 6-month telephone coaching was deployed in the French craft bakery/pastry sector with significant adhesion. Such program appears beneficial for enhancing knowledge and mobilizing skills associated with T2D prevention.
\end{abstract}

\section{Introduction}

Diabetes mellitus now affects 415 million people worldwide, $91 \%$ of whom have type 2 diabetes mellitus [1]. France has not been spared by this increase, with 3.3 million individuals diagnosed with diabetes in 2015 incurring high

Philip Böhme

p.bohme@chru-nancy.fr

1 CHRU de Nancy, Service d'Endocrinologie, Diabétologie, Nutrition, F-54511 Vandœuvre-Lès-Nancy, France

2 Université de Lorraine, EA 4360 APEMAC, F-54000 Nancy, France

3 CHRU Nancy, Plateforme d'Aide à la Recherche Clinique, F54511 Vandœuvre-Lès-Nancy, France

4 MEDIALANE, Plateforme de télésanté, F-54320 Maxéville, France public health costs [2]. Type 2 diabetes is a common chronic disease in both the general and working population, resulting in an increased incidence of absenteeism at work, and increased morbidity and mortality [3, 4]. The rapid increasing prevalence of the disease is largely linked to lifestyle factors associated with overweight, including changes in dietary habits and increasing sedentary behavior [5]. Accordingly, people with significant risk for type 2 diabetes would benefit from early identification and lifestyle intervention [6, 7]. Many authors have proposed diabetes risk scores that can be easily applied in community settings [8-10]. Among these, the Finnish Diabetes Risk Score (FINDRISC) is intended for use directly by non-specialists and recommended by several guidelines [11-15]. Controlled lifestyle interventions can delay the development of type 2 diabetes in high-risk populations although translating these findings into real-world primary healthcare practice or professional environment remains difficult [16-18]. Health coaching is recognized as an innovative strategy to mobilize 
positive health behaviors and probably facilitates prevention actions [19]. In particular, telephone counseling support allows delivering lifestyle interventions in a broad and personalized manner [20].

The aim of this study was first to evaluate the risk of type 2 diabetes in bakery/pastry employees working in France using the FINDRISC score and to subsequently evaluate the effectiveness of a lifestyle intervention by telephone coaching, proposed to the screened individuals with a significant risk for type 2 diabetes.

\section{Methods}

A cross-sectional survey was first conducted to assess the risk of developing type 2 diabetes in bakery/pastry employees working in France. This survey was carried out by Medialane ${ }^{\circledR}$, at the request of the health insurance company in charge of prevention actions for all bakers/ pastry employees in France (AG2R-La Mondiale). Medialane $^{\circledR}$ is a multi-service company specialized in telehealth activities, in particular, health-related surveys or coaching programs by phone.

The database of all employees working in the French bakery/pastry sector $(n=96,039)$ aged $\geq 16$ years, with their names, personal and professional addresses and telephone numbers, was obtained from their health insurance company (exhaustiveness $>90 \%$ ). Employees were contacted by phone by six nurses from Medialane ${ }^{\circledR}$ between May 2015 and May 2016 in random order. Two questions allowed identifying ineligible individuals (i.e., individuals with current diabetes, retired individuals or those who had changed profession) who were subsequently excluded from the screening study. If eligible, employees were asked to participate in a survey to evaluate their 10-year risk of type 2 diabetes. The telephone contacts were discontinued when the inclusion goal of 20,000 individuals was reached. This number was defined from the Medialane nurse resources to conduct the survey and in order to obtain a sufficient precision in the estimation of the mean FINDRISC score $( \pm$ 0.07 , considering a standard deviation of 5 according to previous studies) [21]. The FINDRISC questionnaire used for this survey was developed in 2001 from a cohort study of a representative random sample of the Finnish adult population in order to predict the 10-year incidence of drugtreated type 2 diabetes [9]. It has since been tested in various countries [12, 14, 22, 23]. This questionnaire includes eight items and each self-reported answer is weighted according to the risk increase with a final score ranging from 0 to 26 (Fig. 1). A FINDRISC score lower than 7 is linked to a very low type 2 diabetes risk, 7-11 to a low risk, $12-14$ to a moderate risk, $15-20$ to a high risk, and 21-26 to a very high risk, with these five categories corresponding to a probability of developing type 2 diabetes within the next 10 years of $1 \%, 4 \%, 17 \%, 33 \%$, and $50 \%$, respectively. Anthropometric data (height, weight, waist circumference measured in a horizontal plane, midway between the inferior margin of the ribs, and the superior border of the iliac crest) were self-measured by respondents, with body mass index (BMI) calculated by the Medialane ${ }^{\circledR}$ staff. The Medialane $^{\circledR}$ nurses also collected additional data including gender, type of work (selling vs. production) and whether they worked full- or part-time. The mean duration of this first phone interview was $17 \mathrm{~min}$.

At the end of the screening phase, a coaching program has been proposed to employees aged 16-60 years, who presented either a moderate risk $(12 \leq$ FINDRISC score $\leq$ 14) and overweight or obesity (BMI $\geq 25 \mathrm{~kg} / \mathrm{m}^{2}$ ), or a high or very high risk (FINDRISC score $\geq 15$ ) regardless of their BMI. The coaching program was conducted between June 2015 and March 2017 by the same Medialane ${ }^{\circledR}$ nurse team who performed the screening, all of whom were trained in motivational interviewing. The program consisted of sixmonthly telephone interviews lasting $\sim 20$ minutes, the first and the last (sixth) of which included a short evaluation time of $\sim 5$ min using various tools mentioned hereafter. Throughout these interviews, the nurses assisted the individuals through collaborative conversations with the following incentive messages: more healthy eating, increased daily physical activity, weight management, and stress reduction. A final and seventh telephone interview was scheduled 3 months after the end of the last intervention coaching interview, in order to assess the maintenance of the benefit of the program. Physical activity was estimated by the GPAQ (Global Physical Activity Questionnaire). The GPAQ covers several components of physical activity, such as intensity, duration, and frequency, and it assesses three domains in which physical activity is performed (occupational physical activity, transport-related physical activity, and physical activity during discretionary or leisure time). Finally, it allows classification of the individuals into one of the three following categories linked to activity intensity: 1 (limited), 2 (medium), or 3 (high activity). The English and French versions of this questionnaire are available on the WHO website at https://www.who.int/ncds/surveillance/ steps/GPAQ_EN.pdf and https://www.who.int/ncds/ surveillance/steps/GPAQ_FR.pdf, respectively.

Health-related quality of life was measured using the Short-Form 12 (SF-12), whose final score ranges from 17 (worst quality of life) to 55 (best quality of life) [24, 25]. Dietary knowledge and behavior were assessed by a questionnaire built by the research team (Table 1): each correct answer counting for one point toward the total score. The level of motivation or commitment, inspired by the Prochaska and Di Clemente scheme, was also assessed together by the coaching nurse and the participant, by using only 


\section{TYPE 2 DIABETES RISK ASSESSMENT FORM}

Circle the right alternative and add up your points.
1. Age
$0 \mathrm{p}$. Under 45 years
2 p. $\quad 45-54$ years
3 p. $\quad 55-64$ years
4 p. Over 64 years
2. Body-mass index
(See reverse of form)
0 p. Lower than $25 \mathrm{~kg} / \mathrm{m}^{2}$
1 p. $\quad 25-30 \mathrm{~kg} / \mathrm{m}^{2}$
3 p. Higher than $30 \mathrm{~kg} / \mathrm{m}^{2}$

3. Waist circumference measured below the ribs (usually at the level of the navel)

MEN

WOMEN

0 p. Less than $94 \mathrm{~cm}$

Less than $80 \mathrm{~cm}$

3 p. $\quad 94-102 \mathrm{~cm}$

$80-88 \mathrm{~cm}$

4 p. More than $102 \mathrm{~cm}$

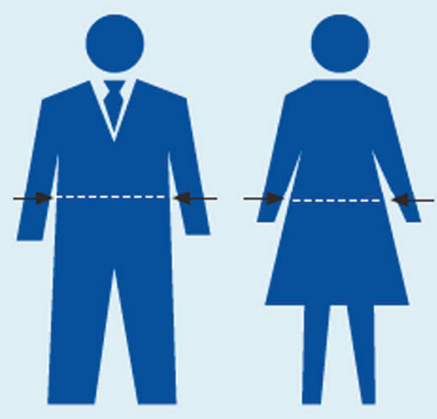

4. Do you usually have daily at least $\mathbf{3 0}$ minutes of physical activity at work and/or during leisure time (including normal daily activity)?

0 p. Yes

2 p. No

5. How often do you eat vegetables, fruit or berries?
0 p. Every day
1 p. Not every day 6. Have you ever taken medication for high
blood pressure on regular basis?

0 p. No

2 p. Yes

7. Have you ever been found to have high blood glucose (eg in a health examination, during an illness, during pregnancy)?

$\begin{array}{ll}0 \text { p. } & \text { No } \\ 5 \text { p. } & \text { Yes }\end{array}$

8. Have any of the members of your immediate family or other relatives been diagnosed with diabetes (type 1 or type 2)?
0p. No
3 p. Yes: grandparent, aunt, uncle or first cousin (but no own parent, brother, sister or child)
5 p. Yes: parent, brother, sister or own child

Please turn over

Test designed by Professor Jaakko Tuomilehto, Department of Public Health, University of Helsinki, and Jaana Lindstrom, MFS, National Public Health Institute.

Fig. 1 The FINDRISC questionnaire (as currently available at https://www.diabetes.fi/files/502/eRiskitestilomake.pdf; accessed 6 December 2018) 
Table 1 Eating knowledge and behavior questionnaire

\begin{tabular}{|c|c|c|}
\hline Categories & Question or assertion & Scoring \\
\hline \multirow[t]{4}{*}{$\begin{array}{l}\text { Knowledge } \\
\text { questions }\end{array}$} & Starchy foods make you fat & $\begin{array}{l}\text { Wrong }=1 \\
\text { Right }=0\end{array}$ \\
\hline & Fish contains less protein than meat & $\begin{array}{l}\text { Wrong }=1 \\
\text { Right }=0\end{array}$ \\
\hline & There is salt in breakfast cereals & $\begin{array}{l}\text { Wrong }=0 \\
\text { Right }=1\end{array}$ \\
\hline & $\begin{array}{l}\text { Frozen products contain fewer } \\
\text { vitamins than fresh products }\end{array}$ & $\begin{array}{l}\text { Wrong }=1 \\
\text { Right }=0\end{array}$ \\
\hline \multirow[t]{4}{*}{$\begin{array}{l}\text { Behavior } \\
\text { questions }\end{array}$} & $\begin{array}{l}\text { Regardless of their form (raw, } \\
\text { cooked, plain or prepared), you } \\
\text { should eat at least } 5 \text { fruits and } \\
\text { vegetables per day }\end{array}$ & $\begin{array}{l}\text { No }=0 \\
\text { Yes }=1\end{array}$ \\
\hline & $\begin{array}{l}\text { You should eat starchy foods (bread, } \\
\text { cereals, potatoes, etc.) at each meal }\end{array}$ & $\begin{array}{l}\text { No }=0 \\
\text { Yes }=1\end{array}$ \\
\hline & $\begin{array}{l}\text { You should consume fish at least } \\
\text { twice a week }\end{array}$ & $\begin{array}{l}\text { No }=0 \\
\text { Yes }=1\end{array}$ \\
\hline & $\begin{array}{l}\text { You should systematically salt your } \\
\text { food before tasting it and you } \\
\text { systematically re-salt your dishes }\end{array}$ & $\begin{array}{l}\text { No }=1 \\
\text { Yes }=0\end{array}$ \\
\hline \multicolumn{2}{|c|}{ Minimum-maximum score } & 0 to 8 \\
\hline
\end{tabular}

four categories: pre-contemplation, contemplation, preparation, and action [26].

The main outcome for the screening phase was the FINDRISC score, considered as a continuous and categorical variable (very low, low, moderate, high, or very high risk). FINDRISC scores were calculated overall, as well as in respondents $\geq 30$ years old, $>45$ years old, and respondents $>45$ years having at least one of the main risk factors for diabetes collected for this survey (BMI $\geq 28 \mathrm{~kg} / \mathrm{m}^{2}$, history of hypertension, or a first degree relative with diabetes) as proposed earlier by the French recommendations [27]. Participation to part or the entire program was also described. Continuous variables are presented as means and standard deviations and categorical variables as numbers and percentages. Three outcomes of interest were used to evaluate the effectiveness of the coaching program: variations in physical activities (GPAQ), in dietary knowledge and behaviors, and in quality of life (SF-12). As these three variables do not follow a normal distribution, results are presented as medians and interquartile ranges. The evaluation of the effects of the coaching program consisted in the comparison of the questionnaire results between the first and the sixth interview, whereas the evaluation of its impact consisted in the comparison between the sixth and the last (seventh) interview (three months after the last coaching interview). A modified intention to treat analysis (mITT) was performed on all individuals with a high FINDRISC score who agreed to participate (whether they were eligible or not) and attended to all telephone interviews [28]. A perprotocol analysis (PP) was focused on the employees eligible for coaching and attended to all interviews. Analyses comparing the scores between interviews one and six (or six and seven) was performed using Wilcoxon signed rank test on paired samples. A symmetry test (equivalent to the McNemar's test but for more than two response modalities) was used on matched nominative data to determine changes in motivation's stages between the first and the last interview. A $P$ value of $<0.05$ for two-sided tests was considered significant. All analyses were performed with SAS version 9.4 (SAS Institute, Inc., Cary, NC, USA).

The survey was conducted according to the principles of the Declaration of Helsinki and approved by a national Ethics Committee (Commission Nationale de l'Informatique et des Libertés). All employees contacted by phone were informed regarding the survey protocol and that their participation in the survey and telephone coaching was voluntary, anonymous and without any compensation.

\section{Results}

Among the 96,039 employees working in the French craft bakery/pastry sector, 30,248 eligible individuals were contacted by phone and asked to participate in the screening survey (Fig. 2). Among these, 20,029 agreed to participate $(66.2 \%)$. The main reason for refusal $(n=10,219)$ was a lack of time to answer questions. The presented results for the screening phase stem from the 19,951 (99.6\%) respondents with no missing data. Among these, 2018 were highrisk individuals eligible for the coaching program. Of the 1, 521 individuals who agreed to participate in this program, 179 did not meet the inclusion criteria since, despite a FINDRISC score between 12 and 14 , but BMI $<25 \mathrm{~kg} / \mathrm{m}^{2}$ ). Finally, 1,348 (66.8\%) eligible individuals accepted to participate and $581(28.8 \%)$ participated in all scheduled interviews (including the seventh).

The characteristics and responses to the FINDRISC questionnaire of the 19,951 screened respondents, the employees eligible for the program and those who agreed to participate in the program are presented in Table 2. Half of the respondents were men $(n=9,891 ; 49.6 \%)$, mean age was $38.0 \pm 13.5$ years and $37.0 \%$ had a BMI $\geq 25 \mathrm{~kg} / \mathrm{m}^{2}$. Their mean FINDRISC score was $5.9 \pm 4.4$ with 802 (4.0\%) participants presenting a 10-year risk of type 2 diabetes $>33 \%$ (score $\geq 15$ ). As a comparison, this high risk was recorded in $554(15.5 \%)$ respondents $>45$ years with classic risk(s) factor(s) for type 2 diabetes. The prevalence of diabetes at 10 years was estimated at $4.4 \%$ overall: $5.6 \%$ in individuals $\geq 30$ years old, $7.0 \%$ in those $>45$ years old, and $11.7 \%$ in those $>45$ years having at least one of the three main risk factors for diabetes. Relative to 1,348 eligible participants taken into account for per-protocol analysis, 1,071 (74.2\%), 951 (70.5\%), 834 (61.9\%), 732 (54.3\%), 


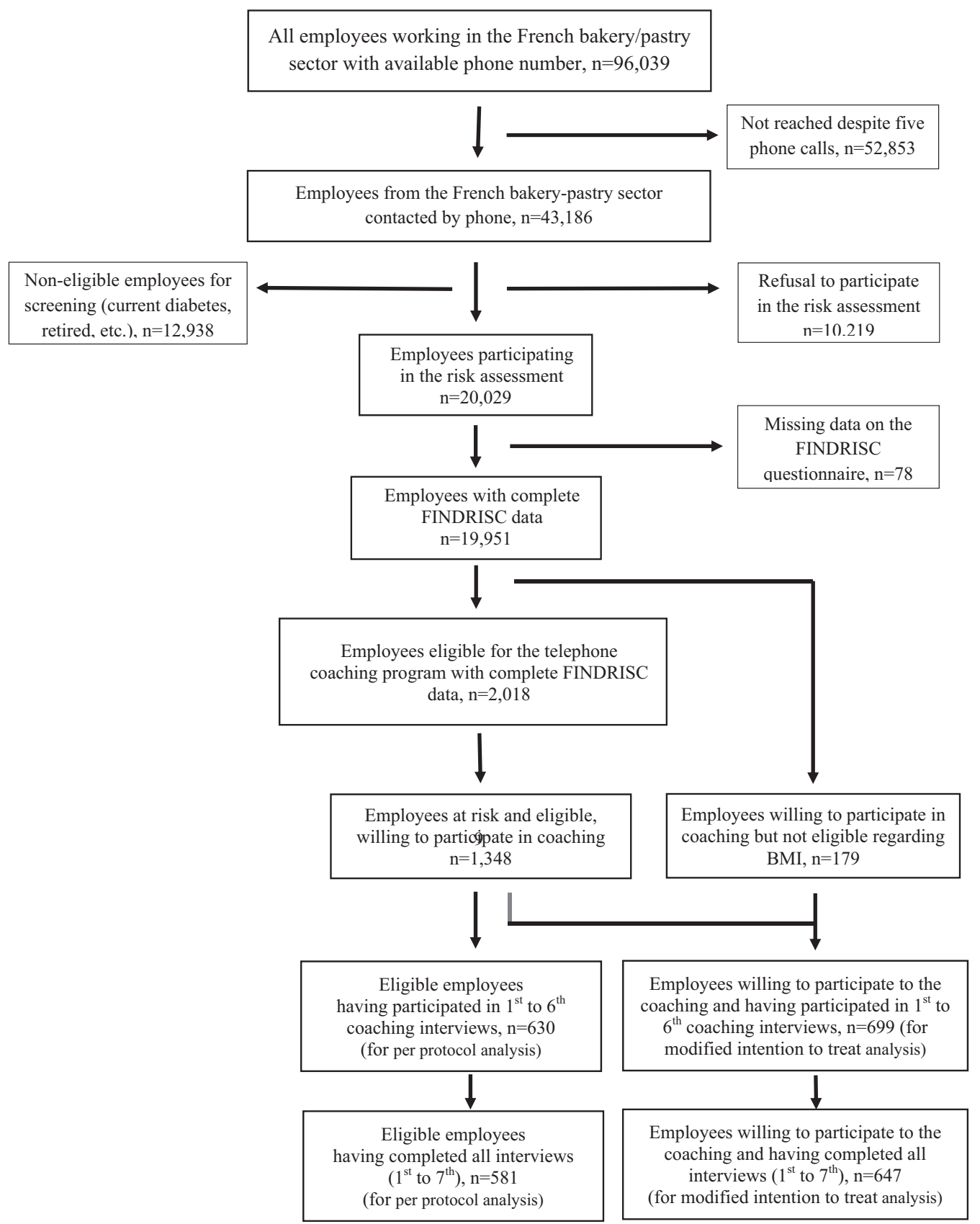

Fig. 2 Study flowchart (including screening and intervention phases)

$681(50.5 \%), 633(47.0 \%)$, and $581(43.1 \%)$ participated in the first, second, third, fourth, fifth, sixth, and seventh interviews, respectively. Among the 581 participants having completed the 7 interviews of the program, 216 were men (37.2\%), the mean age was $48.6 \pm 9.5$ years and their mean FINDRISC score was $14.8 \pm 2.5$. They were slightly older, more corpulent and also had a higher FINDRISC score $(14.8 \pm 2.5$ vs. $14.4 \pm 2.4)$ comparatively to all eligible participants (Table 2).

There was a statistically significant improvement in knowledge and habits linked to the intervention with an increase in observed scores between the first and the sixth interviews (Table 3), whether in mITT $(n=699 / 1,527$ participants accepting to participate in the coaching program whatever the BMI) or PP $(n=630 / 1,348$ participants eligible for the program regarding BMI $)$ analyses $(P<$ 0.0001). Similar significant trends were observed for healthrelated quality of life (mITT and PP analyses) and physical activities (in the mITT analysis only). These data showed an additional improvement in dietary knowledge and habits three months after the coaching program (Table 3), whether the analysis was performed in mITT $(n=647 / 1,527, P<$ 
Table 2 Characteristics of the study participants according to the different stages of the study

\begin{tabular}{|c|c|c|c|c|c|c|c|c|c|}
\hline & & \multicolumn{2}{|c|}{$\begin{array}{l}N=19,951 \text { screened } \\
\text { employees }\end{array}$} & \multicolumn{2}{|c|}{$\begin{array}{l}N=2,018 \text { eligible } \\
\text { employees }\end{array}$} & \multicolumn{2}{|c|}{$\begin{array}{l}N=1,348 \text { Employees } \\
\text { who agreed to } \\
\text { participate }\end{array}$} & \multicolumn{2}{|c|}{$\begin{array}{l}N=581 \text { participants } \\
\text { completing the } \\
\text { program }\end{array}$} \\
\hline & & $N(\%)$ & Mean \pm SD & $N(\%)$ & Mean \pm SD & $N(\%)$ & Mean \pm SD & $N(\%)$ & Mean \pm SD \\
\hline \multirow[t]{2}{*}{ Sex } & Male & 9,891 (49.6) & & $771(38.2)$ & & $489(36.3)$ & & $216(37.2)$ & \\
\hline & Female & $10,060(50.4)$ & & $1,247(61.8)$ & & $859(63.7)$ & & $365(62.8)$ & \\
\hline \multirow[t]{2}{*}{ Work time } & Full-time & $15,770(79.0)$ & & $1,461(72.4)$ & & $972(72.1)$ & & $407(70.1)$ & \\
\hline & Part-time & 4,181 (21.0) & & $557(27.6)$ & & $376(27.9)$ & & $174(29.9)$ & \\
\hline \multirow[t]{2}{*}{ Work type } & Sales & $9,527(47.8)$ & & $1,228(60.9)$ & & $850(63.1)$ & & $363(62.5)$ & \\
\hline & Production & $10,424(52.2)$ & & $790(39.1)$ & & $498(36.9)$ & & $218(37.5)$ & \\
\hline Age (years) & & & $38.0 \pm 13.5$ & & $47.1 \pm 10.8$ & & $47.1 \pm 10.5$ & & $48.6 \pm 9.5$ \\
\hline \multirow[t]{5}{*}{ Age categories (years) } & $<35$ & $8,689(43.6)$ & & $296(14.7)$ & & $190(14.1)$ & & $61(10.5)$ & \\
\hline & $35-44$ & $3,676(18.4)$ & & $373(18.5)$ & & $257(19.1)$ & & $100(17.2)$ & \\
\hline & $45-54$ & 4,959 (24.9) & & $742(36.8)$ & & $515(38.2)$ & & $238(41.0)$ & \\
\hline & $55-64$ & $2,542(12.7)$ & & $589(29.2)$ & & $377(28.0)$ & & $177(30.5)$ & \\
\hline & $\geq 65$ & $85(0.4)$ & & $18(0.9)$ & & $9(0.7)$ & & $5(0.9)$ & \\
\hline BMI $\left(\mathrm{kg} / \mathrm{m}^{2}\right)$ & & & $24.3 \pm 4.5$ & & $30.7 \pm 4.4$ & & $30.7 \pm 4.5$ & & $31.0 \pm 4.4$ \\
\hline \multirow[t]{3}{*}{ BMI categories $\left(\mathrm{kg} / \mathrm{m}^{2}\right)^{\mathrm{a}}$} & Normal & $12,576(63.0)$ & & $66(3.3)$ & & $47(3.5)$ & & $18(3.1)$ & \\
\hline & Overweight & $5,230(26.2)$ & & $870(43.1)$ & & $610(45.3)$ & & $251(43.2)$ & \\
\hline & Obesity & $2,145(10.8)$ & & $1,082(53.6)$ & & $691(51.3)$ & & $312(53.7)$ & \\
\hline \multirow[t]{3}{*}{ WC categories $(\mathrm{cm})^{\mathrm{b}}$} & Normal & $10,611(53.2)$ & & $31(1.5)$ & & $23(1.7)$ & & $10(1.7)$ & \\
\hline & High & $4,741(23.8)$ & & $401(19.9)$ & & $255(18.9)$ & & $88(15.1)$ & \\
\hline & Very high & $4,599(23.1)$ & & $1,586(78.6)$ & & $1,070(79.4)$ & & $483(83.1)$ & \\
\hline $\begin{array}{l}\text { Daily physical } \\
\text { activity (yes) }\end{array}$ & & $14,815(74.3)$ & & $1,038(51.4)$ & & $672(49.9)$ & & $297(51.1)$ & \\
\hline $\begin{array}{l}\text { Daily consumption of } \\
\text { fruits/vegetables (yes) }\end{array}$ & & $1,4506(72.7)$ & & $1,356(67.2)$ & & $900(66.8)$ & & $412(70.9)$ & \\
\hline $\begin{array}{l}\text { History of } \\
\text { antihypertensive drug } \\
\text { treatment (yes) }\end{array}$ & & $1,748(8.8)$ & & $1,338(66.3$ & & $881(65.4)$ & & $369(63.5)$ & \\
\hline $\begin{array}{l}\text { History of high blood } \\
\text { glucose (yes) }\end{array}$ & & $872(4.4)$ & & $1,566(77.6)$ & & $1,007(74.7)$ & & $434(74.7)$ & \\
\hline \multirow[t]{3}{*}{$\begin{array}{l}\text { Family history of } \\
\text { diabetes }\end{array}$} & $\begin{array}{l}1 \text { st degree } \\
\text { relative }\end{array}$ & $3,900(19.5)$ & & $1,327(65.8)$ & & $911(67.6)$ & & $391(67.3)$ & \\
\hline & $\begin{array}{l}\text { 2nd degree } \\
\text { relative }\end{array}$ & $2,952(14.8)$ & & $281(13.9)$ & & $190(14.1)$ & & 73 (12.6) & \\
\hline & No & $13,099(65.7)$ & & $410(20.3)$ & & $247(18.3)$ & & $117(20.1)$ & \\
\hline FINDRISC score & & & $5.9 \pm 4.4$ & & $14.4 \pm 2.4$ & & $14.6 \pm 2.4$ & & $14.8 \pm 2.5$ \\
\hline \multirow[t]{4}{*}{ FINDRISC categories } & Very low & $11,854(59.4)$ & & & & & & & \\
\hline & Low & $5,784(29.0)$ & & & & & & & \\
\hline & Moderate & $1,511(7.6)$ & & $1,217(60.3)$ & & $752(55.8)$ & & $321(55.2)$ & \\
\hline & $\begin{array}{l}\text { High or } \\
\text { very high }\end{array}$ & $802(4.0)$ & & $801(39.7)$ & & $596(44.2)$ & & $260(44.8)$ & \\
\hline
\end{tabular}

${ }^{a}$ BMI categories: normal $<25 \mathrm{~kg} / \mathrm{m}^{2}$; overweight $25-30 \mathrm{~kg} / \mathrm{m}^{2}$; obesity $\geq 30 \mathrm{~kg} / \mathrm{m}^{2}$

${ }^{\mathrm{b}} \mathrm{WC}$ (waist circumference) categories for men: normal $<94 \mathrm{~cm}$; High $=94-102$; very high $>102$-for women: normal $<80 \mathrm{~cm}$; high $=80-88$; very high $>88$ 


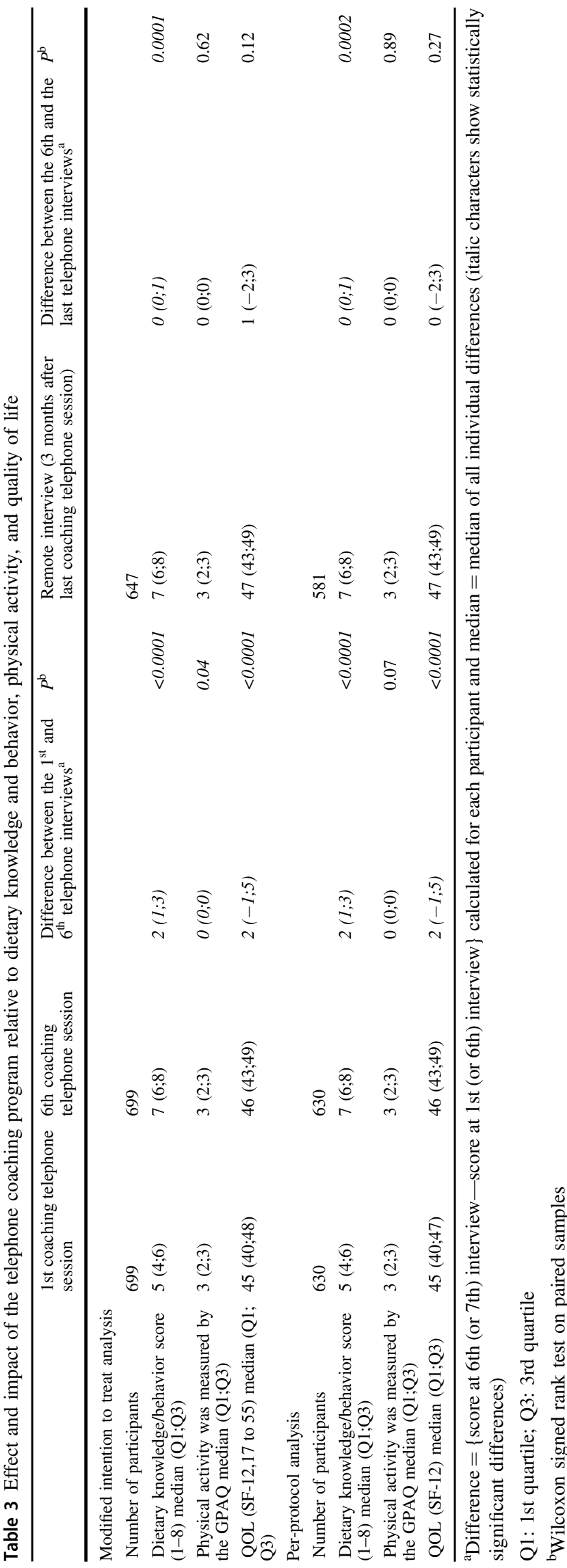

$0.0001)$ or PP $(581 / 1,348, P<0.001)$. Inversely, physical activity, and quality of life scores remained similar.

Stages of change according to the Prochaska and DiClemente classification were evaluated in 653 participants. The proportion of participants considered at the "precontemplation", "contemplation", "preparation", and "action" stages increased from $38.1 \%(n=249), 54.5 \%(n$ $=356), 5.1 \%(n=33)$ and $2.3 \%(n=15)$ to $11.0 \%(n=$ $72), 17.0 \%(n=111), 10.7 \%(n=70)$, and $61.3 \%(n=400)$ between the first and the seventh interviews, respectively. This favorable evolution was statistically significant $(P<$ 0.0001).

\section{Discussion}

This study, conducted on a large sample of employees from the French bakery/pastry sector, led to the identification of $4 \%$ of individuals at a high risk of type 2 diabetes. For employees from moderate to very high risk, the implementation of a health-coaching program via telephone calls appears operational. This program was associated with an improvement in knowledge and skills for dietary and physical activities, as well as quality of life. In addition, a favorable persistent increase in dietary knowledge and behavior at least 3 months after completion of the program was observed.

Our results regarding FINDRISC score in a working population are relatively similar to data from other European populations, whereas lower than that reported in the United States [29, 30]. For example, Vandersmissen and colleagues [21] studied data from 275 Belgian workers undergoing a voluntary health check and found a mean FINDRISC score slightly higher than that recorded herein $(6.8 \pm 4.7$, with $5.5 \%$ of individuals at high or very high risk). To our knowledge, the present study is the first to estimate the 10-year risk of developing type 2 diabetes in a large sample of the French active population. A populationbased study conducted in 67 pharmacies in northeast France from 2007 to 2010 compared the capillary blood glucose measurement and FINDRISC questionnaire in 1907 individuals over 45 years of age having at least one of the main risk factors for type 2 diabetes. The study authors reported that $16.6 \%$ of the participants had a FINDRISC $\geq 15$, which is close to the $15.5 \%$ found in the present study [31]. As well, recent data concerning $>99 \%$ of beneficiaries of a health insurance scheme in France showed an estimated prevalence of pharmacologically treated diabetes, which reached 5\% in 2015 [32]. This rate is similar to this estimated herein in individuals $\geq 30$ years old. Hence, it could be argued that the risk of type 2 diabetes in French bakery/ pastry employees likely does not differ from the overall French adult population. 
Progression of prediabetes to type 2 diabetes may be prevented through favorable lifestyle interventions [18]. However, initiating and maintaining healthy lifestyle changes remain a genuine challenge [33]. Health coaching through telephone interviews is one of the emerging tools that have been shown to improve favorable health behaviors in patients suffering from chronic diseases such type 2 diabetes, as well as for prediabetes $[34,35]$. With regard to studies performed in the workplace, Wilson et al. [36] published selected data from a randomized controlled trial conducted in 418 city/county employees in order to analyze the impact of the "Fuel Your Life" program. Three interventions were used: small group coaching, self-study and telephone coaching, the latter representing the best strategy with $28.3 \%$ of the participants of this group losing $5 \%$ or more of their body weight [36]. As our strategy, a few authors have proposed to condition a coaching-type intervention to a risk estimation by the FINDRISC score, which was also positively used as a criterion of effectiveness [37]. Finally, the telephone coaching proposed in the present study shows encouraging results in terms of favorable dietary behaviors and commitment toward an enhanced prevention of type 2 diabetes. Telephone coaching is one of the available technology-assisted interventions for diabetes prevention, even if the ideal combination of these technologies still necessitates further assessment and impact studies, including its cost-effectiveness [38-40]. For example, such a positive and lasting impact is not found in all studies despite enhanced physical activity [41].

The substantial number of included individuals herein for screening and intervention constitutes one of the strengths of the present study. Indeed, other published data including such high number of individuals from the professional sector remain rare [29]. However, our results should be interpreted with caution. For the screening survey, we cannot affirm that all those who were not contacted by telephone or did not wish to participate did not differ from respondents. Moreover, answers to all items of the FINDRISC questionnaire were self-reported, such that we cannot exclude errors in certain responses. The choice of the FINDRISC score can also be debated. Indeed, other nonbiological tools are also available. For example, the German Diabetes Risk Score was derived from the European Prospective Investigation into Cancer and Nutrition (EPIC)Potsdam Study and includes information on age, waist circumference, height, history of hypertension, physical activity, and consumption of alcohol, coffee, whole grains, and red meat [42]. The American Diabetes Association type 2 diabetes risk test is also widely used and includes seven questions for which a user can score up to 11 points with the threshold for people at risk being at 5 points [10]. Other scores are well published, including the Canadian diabetes risk questionnaire (CANRISK), the Australian type 2 diabetes risk assessment tool (AUSDRISK), and the QDiabetes risk model built from a large cohort of patients in England and Wales [43-45]. All of these risk scores show overall good discriminatory ability in populations for whom they were developed [46]. However, discriminatory performance is more heterogeneous and generally weaker in external populations [47]. Other limitations of this study include the short time span (3 months later) used to evaluate the impact of the coaching program and the lack of a control group. Finally, a short self-constructed questionnaire was used for dietary knowledge and behavior (four questions per domain), which was designed for this specific study and not validated by adapted studies [48]. Although our data suggest that targeting both nutritional knowledge and motivation can together mobilize skills and likely favor type 2 diabetes prevention, it is nonetheless difficult in this particular instance to distinguish the effects between acquiring knowledge and boosting motivation per se, both being also related to the quality of the relationship [49]. Another point is the acceptability of such a program: the number of individuals who ultimately accepted and participated to all interviews of the coaching program could be considered as low (approximately onethird) compared with the number of individuals at high risk. However, prevention programs aimed at reducing this risk can have a significant and large impact if they are implemented on a large scale [50].

\section{Conclusion}

Although the observed data remain to be confirmed, this study demonstrated that employees from the French craft bakery/pastry sector have a similar risk of type 2 diabetes than other general European populations, including France. The combination of risk screening using the FINDRISC score and the 6-month telephone health-coaching program conducted in a professional environment furthermore appears effective, showing encouraging results on both motivation and favorable behaviors, which could help prevent type 2 diabetes.

Acknowledgements We thank all of the employees of the French craft bakery/pastry sector who participated in this study. This work was supported by the health department of the French craft bakery/pastry sector, insured by AG2R-La Mondiale, at the request of the social partners of the profession. However, the latter were not involved in this survey or its analysis.

Author contributions PG and NT conceived and designed the study; $\mathrm{PB}, \mathrm{AL}, \mathrm{PG}$, and NT contributed to data acquisition, or analysis and interpretation; $\mathrm{PB}$ and NT wrote the manuscript; and all authors revised, reviewed, and approved the final version of the manuscript. The data sets generated and/or analyzed during the current study are available from the corresponding author on reasonable request. 


\section{Compliance with ethical standards}

Conflict of interest The authors declare that they have no competing interests.

Publisher's note: Springer Nature remains neutral with regard to jurisdictional claims in published maps and institutional affiliations.

Open Access This article is licensed under a Creative Commons Attribution 4.0 International License, which permits use, sharing, adaptation, distribution and reproduction in any medium or format, as long as you give appropriate credit to the original author(s) and the source, provide a link to the Creative Commons license, and indicate if changes were made. The images or other third party material in this article are included in the article's Creative Commons license, unless indicated otherwise in a credit line to the material. If material is not included in the article's Creative Commons license and your intended use is not permitted by statutory regulation or exceeds the permitted use, you will need to obtain permission directly from the copyright holder. To view a copy of this license, visit http://creativecommons. org/licenses/by/4.0/.

\section{References}

1. Federation ID. IDF Diabetes Atlas, 8th edn. International Diabetes Federation: Brussels, Belgium, 2017.

2. de Lagasnerie G, Aguade AS, Denis P, Fagot-Campagna A, Gastaldi-Menager C. The economic burden of diabetes to French national health insurance: a new cost-of-illness method based on a combined medicalized and incremental approach. Eur $\mathbf{J}$ Health Econ. 2018;19:189-201.

3. Dray-Spira R, Herquelot E, Bonenfant S, Gueguen A, Melchior M. Impact of diabetes mellitus onset on sickness absence from work-a 15-year follow-up of the GAZEL Occupational Cohort Study. Diabet Med. 2013;30:549-56.

4. Viitasalo K, Lindstrom J, Hemio K, Puttonen S, Koho A, Harma $\mathrm{M}$, et al. Occupational health care identifies risk for type 2 diabetes and cardiovascular disease. Prim Care Diabetes. 2012;6:95-102.

5. Hu FB, Manson JE, Stampfer MJ, Colditz G, Liu S, Solomon CG, et al. Diet, lifestyle, and the risk of type 2 diabetes mellitus in women. N Engl J Med. 2001;345:790-7.

6. Vermunt PW, Milder IE, Wielaard F, de Vries JH, Baan CA, van Oers JA, et al. A lifestyle intervention to reduce Type 2 diabetes risk in Dutch primary care: 2.5-year results of a randomized controlled trial. Diabet Med. 2012;29:e223-231.

7. Tuomilehto J, Lindstrom J, Eriksson JG, Valle TT, Hamalainen H, Ilanne-Parikka P, et al. Prevention of type 2 diabetes mellitus by changes in lifestyle among subjects with impaired glucose tolerance. N Engl J Med. 2001;344:1343-50.

8. Nanri A, Nakagawa T, Kuwahara K, Yamamoto S, Honda T, Okazaki H, et al. Development of risk score for predicting 3-year incidence of type 2 diabetes: japan epidemiology collaboration on occupational health study. PLoS ONE. 2015;10:e0142779.

9. Lindstrom J, Tuomilehto J. The diabetes risk score: a practical tool to predict type 2 diabetes risk. Diabetes Care. 2003;26:725-31.

10. Bang H, Edwards AM, Bomback AS, Ballantyne CM, Brillon D, Callahan MA, et al. Development and validation of a patient selfassessment score for diabetes risk. Ann Intern Med. 2009;151:775-83.

11. Authors/Task Force M, Ryden L, Grant PJ, Anker SD, Berne C, Cosentino F, et al. ESC Guidelines on diabetes, pre-diabetes, and cardiovascular diseases developed in collaboration with the
EASD: the Task Force on diabetes, pre-diabetes, and cardiovascular diseases of the European Society of Cardiology (ESC) and developed in collaboration with the European Association for the Study of Diabetes (EASD). Eur Heart J. 2013;34:3035-87.

12. Hellgren MI, Petzold M, Bjorkelund C, Wedel H, Jansson PA, Lindblad U. Feasibility of the FINDRISC questionnaire to identify individuals with impaired glucose tolerance in Swedish primary care. A cross-sectional population-based study. Diabet Med. 2012;29:1501-5.

13. Lindstrom J, Neumann A, Sheppard KE, Gilis-Januszewska A, Greaves CJ, Handke U, et al. Take action to prevent diabetes-the IMAGE toolkit for the prevention of type 2 diabetes in Europe. Horm Metab Res. 2010;42:S37-55.

14. Makrilakis K, Liatis S, Grammatikou S, Perrea D, Stathi C, Tsiligros $\mathrm{P}$, et al. Validation of the Finnish diabetes risk score (FINDRISC) questionnaire for screening for undiagnosed type 2 diabetes, dysglycaemia and the metabolic syndrome in Greece. Diabetes Metab. 2011;37:144-51.

15. Paulweber B, Valensi P, Lindstrom J, Lalic NM, Greaves CJ, McKee M, et al. A European evidence-based guideline for the prevention of type 2 diabetes. Horm Metab Res. 2010;42:S3-36.

16. Diabetes Prevention Program Research G. The 10-year costeffectiveness of lifestyle intervention or metformin for diabetes prevention: an intent-to-treat analysis of the DPP/DPPOS. Diabetes Care. 2012;35:723-30.

17. Jolly K, Lewis A, Beach J, Denley J, Adab P, Deeks JJ, et al. Comparison of range of commercial or primary care led weight reduction programmes with minimal intervention control for weight loss in obesity: lighten Up randomised controlled trial. BMJ. 2011;343:d6500.

18. Knowler WC, Barrett-Connor E, Fowler SE, Hamman RF, Lachin $\mathrm{JM}$, Walker EA, et al. Reduction in the incidence of type 2 diabetes with lifestyle intervention or metformin. N Engl J Med. 2002;346:393-403.

19. Hill B, Richardson B, Skouteris H. Do we know how to design effective health coaching interventions: a systematic review of the state of the literature. Am J Health Promot. 2015;29:e158-168.

20. Digenio AG, Mancuso JP, Gerber RA, Dvorak RV. Comparison of methods for delivering a lifestyle modification program for obese patients: a randomized trial. Ann Intern Med. 2009;150:255-62.

21. Vandersmissen GJ, Godderis L. Evaluation of the Finnish Diabetes Risk Score (FINDRISC) for diabetes screening in occupational health care. Int $\mathrm{J}$ Occup Med Environ Health. 2015;28:587-91.

22. Bergmann A, Li J, Wang L, Schulze J, Bornstein SR, Schwarz PE. A simplified Finnish diabetes risk score to predict type 2 diabetes risk and disease evolution in a German population. Horm Metab Res. 2007;39:677-82.

23. Schwarz PE, Lindstrom J, Kissimova-Scarbeck K, Szybinski Z, Barengo NC, Peltonen M, et al. The European perspective of type 2 diabetes prevention: diabetes in Europe-prevention using lifestyle, physical activity and nutritional intervention (DE-PLAN) project. Exp Clin Endocrinol Diabetes. 2008;116:167-72.

24. Kudielka BM, Hanebuth D, von Kanel R, Gander ML, Grande G, Fischer JE. Health-related quality of life measured by the SF12 in working populations: associations with psychosocial work characteristics. J Occup Health Psychol. 2005;10:429-40.

25. Wanner M, Hartmann C, Pestoni G, Martin BW, Siegrist M, Martin-Diener E. Validation of the Global Physical Activity Questionnaire for self-administration in a European context. BMJ Open Sport Exerc Med. 2017;3:e00206.

26. Prochaska JO, Goldstein MG. Process of smoking cessation. Implications for clinicians. Clin Chest Med. 1991;12:727-35.

27. ANAES-Service évaluation des technologies et service évaluation économique. PRINCIPES DE DEPISTAGE DU DIABETE DE TYPE 2. 2003. 
28. Abraha I, Montedori A. Modified intention to treat reporting in randomised controlled trials: systematic review. BMJ. 2010;340: c2697.

29. Gyberg V, Hasson D, Tuomilehto J, Ryden L. Measuring risk online-feasibility of using FINDRISC in an online workplace survey. Prim Care Diabetes. 2012;6:103-7.

30. Zhang L, Zhang Z, Zhang Y, Hu G, Chen L. Evaluation of Finnish Diabetes Risk Score in screening undiagnosed diabetes and prediabetes among U.S. adults by gender and race: NHANES 19992010. PLoS ONE. 2014;9:e97865.

31. Böhme P, Agrinier N, Badia M, Durand M, Scheen A, Guillaume M. Campagnes de sensibilisation au dépistage du diabète de type 2 dans les pharmacies. Comparaison de deux approches : glycémie capillaire et grille Findrisc. Diabetes Metab. 2012;38:A7.

32. Mandereau-Bruno L, Fosse-Edorh S. Prévalence du diabète traité pharmacologiquement (tous types) en France en 2015. Disparités territoriales et socio-économiques. Bull Epidémiol Hebd 2017;586-91.

33. Greenway FL. Physiological adaptations to weight loss and factors favouring weight regain. Int J Obes (Lond). 2015;39:1188-96.

34. Dennis SM, Harris M, Lloyd J, Powell Davies G, Faruqi N, Zwar N. Do people with existing chronic conditions benefit from telephone coaching? A rapid review. Aust Health Rev. 2013;37:381-8.

35. Michaelides A, Raby C, Wood M, Farr K, Toro-Ramos T. Weight loss efficacy of a novel mobile Diabetes Prevention Program delivery platform with human coaching. BMJ Open Diabetes Res Care. 2016;4:e000264.

36. Wilson MG, DeJoy DM, Vandenberg RJ, Corso P, Padilla H, Zuercher H. Effect of intensity and program delivery on the translation of diabetes prevention program to worksites: a randomized controlled trial of fuel your life. J Occup Environ Med. 2016;58:1113-20.

37. Wennehorst K, Mildenstein K, Saliger B, Tigges C, Diehl H, Keil $\mathrm{T}$, et al. A Comprehensive Lifestyle Intervention to Prevent Type 2 Diabetes and Cardiovascular Diseases: the German CHIP Trial. Prev Sci. 2016;17:386-97.

38. Fischer HH, Fischer IP, Pereira RI, Furniss AL, Rozwadowski JM, Moore SL, et al. Text message support for weight loss in patients with prediabetes: a randomized clinical trial. Diabetes Care. 2016;39:1364-70.

39. Grock S, Ku JH, Kim J, Moin T. A review of technology-assisted interventions for diabetes prevention. Curr Diab Rep. 2017;17:107.
40. Odnoletkova I, Ramaekers D, Nobels F, Goderis G, Aertgeerts B, Annemans L. Delivering diabetes education through nurse-led telecoaching. cost-effectiveness analysis. PLoS ONE. 2016;11: e0163997.

41. O'Hara BJ, Phongsavan P, Eakin EG, Develin E, Smith J, Greenaway M, et al. Effectiveness of Australia's Get Healthy Information and Coaching Service: maintenance of self-reported anthropometric and behavioural changes after program completion. BMC Public Health. 2013;13:175.

42. Schulze MB, Hoffmann K, Boeing H, Linseisen J, Rohrmann S, Mohlig M, et al. An accurate risk score based on anthropometric, dietary, and lifestyle factors to predict the development of type 2 diabetes. Diabetes Care. 2007;30:510-5.

43. Chen L, Magliano DJ, Balkau B, Colagiuri S, Zimmet PZ, Tonkin AM, et al. AUSDRISK: an Australian Type 2 Diabetes Risk Assessment Tool based on demographic, lifestyle and simple anthropometric measures. Med J Aust. 2010;192:197-202.

44. Hippisley-Cox J, Coupland C, Robson J, Sheikh A, Brindle P. Predicting risk of type 2 diabetes in England and Wales: prospective derivation and validation of QDScore. BMJ. 2009;338: b880.

45. Robinson CA, Agarwal G, Nerenberg K. Validating the CANRISK prognostic model for assessing diabetes risk in Canada's multi-ethnic population. Chronic Dis Inj Can. 2011;32:19-31.

46. Balkau B, Lange C, Fezeu L, Tichet J, de Lauzon-Guillain B, Czernichow S, et al. Predicting diabetes: clinical, biological, and genetic approaches: data from the Epidemiological Study on the Insulin Resistance Syndrome (DESIR). Diabetes Care. 2008;31:2056-61.

47. Buijsse B, Simmons RK, Griffin SJ, Schulze MB. Risk assessment tools for identifying individuals at risk of developing type 2 diabetes. Epidemiol Rev. 2011;33:46-62.

48. Schenker N, Raghunathan TE, Bondarenko I. Improving on analyses of self-reported data in a large-scale health survey by using information from an examination-based survey. Stat Med. 2010;29:533-45.

49. Rockette-Wagner B, Edelstein S, Venditti EM, Reddy D, Bray GA, Carrion-Petersen ML, et al. The impact of lifestyle intervention on sedentary time in individuals at high risk of diabetes. Diabetologia. 2015;58:1198-202.

50. Aziz Z, Absetz P, Oldroyd J, Pronk NP, Oldenburg B. A systematic review of real-world diabetes prevention programs: learnings from the last 15 years. Implement Sci. 2015;10:172. 